\title{
Comment
}

Neuroepidemiology 2010;34:230-231

DOI: $\underline{10.1159 / 000297745}$

\section{Obesity-Associated Cognitive Decline: Excess Weight Affects More than the Waistline}

Ronald A. Cohen

Department of Psychiatry and Human Behavior, Brown University, Providence, R.I., USA

Increasing interest and concern over the effects of chronic obesity on public health reflects growing evidence that obesity has reached epidemic proportions in this country [1]. It is now wellknown that chronic obesity is associated with an increased risk of a variety of different diseases, including diabetes, cardiovascular disease, and cancer $[2,3]$. Obesity is also associated with a number of neurological disorders, most notably stroke and sleep disturbance $[4,5]$, as well as psychiatric and psychosocial problems [6]. The pathophysiological bases for the relationships between obesity and some of these co-morbidities are relatively well understood. For example, obesity is a primary determinant of metabolic syndrome, which is strongly linked to diabetes, cardiovascular disease, and stroke [7].

Given that both diabetes and vascular disease have been linked to brain dysfunction [8-10], and that many of the risk factors associated with obesity are known to contribute to cerebrovascular disease, it is not altogether surprising that chronic obesity is associated with cognitive impairment. However, the fact that obesity is associated with reduced cognitive function among people without significant medical co-morbidity is noteworthy, particularly when efforts are made to exclude people with co-morbidities that are known to affect the brain [11]. Furthermore, epidemiological studies have linked obesity and metabolic syndrome to neurodegenerative brain disturbances [12-14]. A number of cross-sectional studies have examined obesity and cognitive function over the past several years, but relatively few have examined these relationships longitudinally, and fewer still have analyzed change in body composition and cognitive function simultaneously. Effort to understand how obesity may lead to cognitive decline requires this type of analysis in both overweight and underweight individuals. It is against this backdrop that the current analysis of data from the Baltimore Longitudinal Study of Aging should be considered [15].

Body mass index (BMI) and the other measures of obesity were shown to be associated with both cross-sectional and longitudinal cognitive function in a large $(\mathrm{n}=1,703)$ middle-aged community sample. The fact that greater BMI was linked to declines in overall cognitive and memory performance suggests that obesity may be contributing to premature brain aging. People with pre-existing medical conditions (e.g. AD, stroke, and myocardial infarction) were excluded from the study, so the BMI effects on cognition cannot be dismissed as simply a byproduct of other co-morbidities. Furthermore, the cohort on average was not severely obese, so the observed relationships between the obesity indices and cognition were occurring in the context of a typical community sample. Two risk factors associated with metabolic syndrome tended to be very prevalent: type 2 diabetes/glucose intolerance (41.9\%) and hypertension (35.0\%). Significant associations between obesity and cognitive function remained after controlling for these factors. Yet, it is possible that living with chronic metabolic and vascular risk factors has a cumulative effect on the brain even when there is no history of cardiovascular or cerebrovascular events. Future analyses aimed at the question of whether people showed different cognitive trajectories based on these risk factors would be valuable.

Cognition was assessed on a comprehensive neuropsychological battery, which is atypical for most epidemiological studies. This enabled the specificity of cognitive effects to be tested. Attention and processing speed tend to be particularly vulnerable in chronic systemic vascular disease [8], so one might predict that these cognitive domains would be most affected if the effects of chronic obesity on cognitive function are vascular in origin. This was not the case. The obesity indices were most strongly associated with global cognitive function and memory. Surprisingly, stronger attention and visual spatial function were associated with greater BMI in the cohort, a finding that suggests that the relationship between obesity and cognitive function is complicated and requires further examination.

The mechanisms underlying the linkage between obesity and cognitive function are not well understood and likely involve multiple pathways that interact with each other. The authors discuss plausible vascular and metabolic mechanisms, as well as other studies linking obesity with abnormalities of $\beta$-amyloid metabolism, dopamine dysfunction, brain-derived neurotrophic factor, leptin, and pro-inflammatory cytokines. Ultimately, how all of these factors interact to affect brain function is not well understood. Additional research is needed to disentangle the pathophysiological mechanisms underlying obesity-associated brain dysfunction. Prospective studies of people who lose substantial weight through behavioral methods and bariatric surgery may be helpful in this regard. The current study by Gunstad et al. [15] provides a good starting point for these efforts, providing strong evidence that chronic obesity affects the brain and cognitive function over time.

\section{KARGER}

Fax +41613061234 E-Mail karger@karger.ch www.karger.com
() 2010 S. Karger AG, Basel

$0251-5350 / 10 / 0344-0230 \$ 26.00 / 0$ 


\section{References}

$\checkmark 1$ Hedley AA, Ogden CL, Johnson CL, Carroll MD, Curtin LR, Flegal KM: Prevalence of overweight and obesity among us children, adolescents, and adults, 1999-2002. JAMA 2004;291:2847-2850.

-2 Dong M, Giles WH, Felitti VJ, Dube SR, Williams JE, Chapman DP, Anda RF: Insights into causal pathways for ischemic heart disease: adverse childhood experiences study. Circulation 2004;110:1761-1766.

3 Dixon JB: The effect of obesity on health outcomes. Mol Cell Endocrinol 2010;316:104-108.

-4 Olsen TS, Dehlendorff C, Petersen HG, Andersen KK: Body mass index and poststroke mortality. Neuroepidemiology 2008;30:93-100.

5 Sivertsen B, Krokstad S, Overland S, Mykletun A: The epidemiology of insomnia: associations with physical and mental health. The HUNT-2 study. J Psychosom Res 2009;67:109-116.

6 Black DW, Goldstein RB, Mason EE: Prevalence of mental disorder in 88 morbidly obese bariatric clinic patients. Am J Psychiatry 1992;149: 227-234.

7 Sacks FM: Metabolic syndrome: epidemiology and consequences. J Clin Psychiatry 2004;65(suppl 18):3-12.

$\checkmark 8$ Cohen RA, Poppas A, Forman DE, Hoth KF, Haley AP, Gunstad J, Jefferson AL, Tate DF, Paul RH, Sweet LH, Ono M, Jerskey BA, GerhardHerman M: Vascular and cognitive functions associated with cardiovascular disease in the elderly. J Clin Exper Neuropsychol 2009;31: 96-110.

9 Liew G, Mitchell P, Wong TY, Lindley RI, Cheung N, Kaushik S, Wang JJ: Retinal microvascular signs and cognitive impairment. J Am Geriatr Soc 2009;57:1892-1896.

10 Okereke OI, Kang JH, Cook NR, Gaziano JM, Manson JE, Buring JE, Grodstein F: Type 2 diabetes mellitus and cognitive decline in two large cohorts of community-dwelling older adults. J Am Geriatr Soc 2008; 56:1028-1036.
11 Gunstad J, Spitznagel MB, Paul RH, Cohen RA, Kohn M, Luyster FS, Clark R, Williams LM, Gordon E: Body mass index and neuropsychological function in healthy children and adolescents. Appetite 2008;50: 246-251.

12 Cereda E, Sacchi MC, Malavazos AE: Central obesity and increased risk of dementia more than three decades later. Neurology 2009;72: 1030-1031, author reply 1031.

13 Craft S: The role of metabolic disorders in Alzheimer disease and vascular dementia: two roads converged. Arch Neurol 2009;66:300-305.

14 Hughes TF, Borenstein AR, Schofield E, Wu Y, Larson EB: Association between late-life body mass index and dementia: the Kame project. Neurology 2009;72:1741-1746.

15 Gunstad J, Lhotsky A, Wendell CR, Ferrucci L, Zonderman AB: Longitudinal examination of obesity and cognitive function: results from the Baltimore Longitudinal Study of Aging. Neuroepidemiology 2010; 34:222-229.

Prof. Ronald A. Cohen

Department of Psychiatry and Human Behavior

Box G-BH, Brown University

Providence, RI 02912 (USA)

Tel. +1 401793 8787, Fax +1 4017938709

E-Mail rcohen@lifespan.org 